\title{
ANA, ADOLESCENTE NOTA DEZ? REFLEXÕES SOBRE A PATOLOGIZAÇÃO DO APRENDER
}

\author{
Cristiana Carneiro (UFRJ)* \\ https://orcid.or/0000-0002-4042-1155 \\ Raisa de Paula Fernandes da Silva (SEMEC/RJ)** \\ https://orcid.or/0000-0003-0047-8891
}

\section{RESUMO}

0 artigo tem como objetivo discutir entraves na escolarização a partir de um estudo de caso realizado com uma adolescente diagnosticada com Transtorno Opositivo Desafiador (TOD), Transtorno do Déficit de Atenção com Hiperatividade (TDAH) e dificuldade de aprendizagem. ${ }^{1}$ Para isto, buscamos aprofundar o tema das dificuldades de aprendizagem a fim de tecer uma reflexão sobre o diagnóstico de Ana no que se dirige ao aprender. Discutimos a diferença entre a preponderância do organismo em detrimento do corpo nas leituras sobre entraves no aprender e sua relação com a patologização. Termos como mal-estar, estilos cognitivos e de aprendizagem foram utilizados para ampliar o debate sobre as dificuldades em estar na escola e responder às suas demandas. Esta ampliação permitiu uma nova compreensão sobre o aprender e sua relação com a escola.

Palavras-chave: Dificuldades de aprendizagem. Medicalização. Estudo de caso. Mal-estar. Educação.

\section{ABSTRACT}

\section{ANA, TEENAGER GRADE 10? REFLECTIONS ON THE PATHOLOGIZATION OF LEARNING}

The following article aims to understand what they are learning difficulties from a case study of an adolescent diagnosed with Oppositional Defiant Disorder (ODD), Attention Deficit Disorder with Hyperactivity (ADHD) and learning disabilities. For this we seek to deepen on the subject in order to better understand how learning disabilities are defined / reputable, so we could review the case and make sure that it would set up this diagnosis. Discusses the difference between the preponderance of the body over the body in the readings

\footnotetext{
* Pós-doutorado pela Universidade de Paris VII. Doutora em Psicologia pela Universidade Federal do Rio de Janeiro (UFRJ). Professora Associada Faculdade de Educação e do Programa de Pós-graduação em Psicologia da Universidade Federal do Rio de Janeiro (UFRJ).E-mail: cristianacarneiro13@gmail.com

** Professora de Ensino Fundamental I da rede municipal do Rio de Janeiro. E-mail: raisadepaula@gmail.com

1 Graduada em Pedagogia pela Universidade Federal do Rio de Janeiro (UFRJ). A pesquisa Infância, adolescência e mal-estar na escolarização: estudo de casos em psicanálise e educação (CARNEIRO; COUTINHO, 2016), sob protocolo 28671414.1.0000.5243, teve aprovação no comitê de ética no 789.946
} 
on barriers to learning and its relationship with pathologization. Terms such as malaise, cognitive styles and learning were used to broaden debate about the difficulties of learning. This expansion has enabled a new understanding of the diagnosis of adolescents in relation to school.

Keywords: Learning disabilities. Medication. Case study. Malaise. Education.

\section{RESUMEN}

\section{ANA, ¿ADOLESCENTE DE $10^{\circ}$ GRAD0? REFLEXIONES SOBRE LA PATOLOGIZACIÓN DEL APRENDIZAJE}

El artículo tiene como objetivo discutir los obstáculos en la escolarización a partir de un estudio de caso realizado con un adolescente al que se le diagnosticó Trastorno de Oposición Desafiante (TDA), Trastorno de Déficit de Atención e Hiperactividad (TDAH) y problemas de aprendizaje. Para ello, se buscó profundizar en el tema de las dificultades de aprendizaje para tejer una reflexión sobre el diagnóstico de Ana en lo que se refiere al aprendizaje. Discute la diferencia entre la preponderancia del cuerpo sobre el cuerpo en las lecturas sobre las barreras al aprendizaje y su relación con la patologización. Se utilizaron términos como "malestar", "estilos cognitivos y de aprendizaje" para ampliar el debate sobre las dificultades para estar en la escuela y responder a sus demandas. Esta expansión permitió una nueva comprensión del aprendizaje y su relación con la escuela.

Palabras clave: Dificultades de aprendizaje. Medicalización. Estudio de casos. Malestar. Educación.

\section{Introdução}

Partindo de um diagnóstico entendido por nós como enigmático, pois era estranho à realidade vivida e observada das pesquisadoras com a adolescente, nos voltamos para as questões que envolviam o mal-estar de Ana em relação à escola e suas demandas. 0 objetivo não foi dar um novo diagnóstico ou ratificar o já dito, mas pô-lo em questão, no bom sentido do termo. Justamente no sentido da Resolução no 177 (BRASIL, 2015) do Conselho Nacional dos Direitos da Criança e do Adolescente (CONANDA), que assegura o direito de crianças e adolescentes não serem submetidos à excessiva medicalização, entendendo por isso a redução inadequada de questões de aprendizagem, comportamento e disciplina a patologias. Motivadas, então, por uma ampliação das questões que levaram Ana a um serviço de saúde mental da infância e adolescência, voltamo-nos para o aprender e seus percalços.
0 artigo se originou da interlocução entre uma pesquisa de campo e um de seus derivativos, um trabalho monográfico realizado na Faculdade de Educação da Universidade Federal do Rio de Janeiro (UFRJ). Teve como objetivo principal refletir sobre o diagnóstico de dificuldade de aprendizagem dado a uma adolescente de 15 anos, a partir de um estudo de caso. Este estudo se deu num contexto maior de pesquisa, pois foi parte da pesquisa Infância, adolescência e mal-estar na escolarização: estudo de casos em psicanálise e educação (CARNEIRO; COUTINHO, 2016). A partir do interesse em discutirmos os entraves de aprendizagem e a possível patologização do aprender, surgiu também o interesse em buscar alternativas de compreensão para aqueles que não aprendem de acordo com o padrão, com o que se espera deles. Após apresentarmos um recorte desta discussão no presente texto, trazemos o caso, 
onde foi importante escutarmos o que a própria adolescente disse sobre seu processo de escolarização e o aprender. Numa pesquisa onde a voz do sujeito foi compreendida como seu fundamento, escutar e mapear este lugar foi um dos objetivos centrais da pesquisa-intervenção. Não obstante, também visou entender como sua família viu esse processo e ouvir os pais, bem como os especialistas, que no caso foram um psiquiatra e uma psicóloga. Compreender, ainda, o que a escola dizia sobre a adolescente no meio escolar, sobretudo em relação à aprendizagem. Desta forma, o artigo segue os quatro eixos que foram trabalhados durante o tempo de pesquisa, os discursos da adolescente, dos pais, da escola e dos especialistas, mostrando suas convergências, divergências e paradoxos.

A metodologia utilizada na pesquisa ampliada foi o estudo de casos múltiplos (CARNEIRO, 2018), aliado à pesquisa-intervenção, indicado ao estudo de fenômenos complexos e em tempo real, no sentido de que a pesquisa se deu ao mesmo tempo que a intervenção. 0 estudo de Ana foi realizado durante dois anos, conjuntamente a mais um adolescente e três crianças, ainda que no presente trabalho só a ela nos dedicaremos. 0 material foi construído a partir de reuniões com os pais da adolescente, a própria adolescente, a escola onde ela estudou e os especialistas que a atenderam no Instituto de Psiquiatria da Universidade Federal do Rio de Janeiro (IPUB-UFRJ). A construção do material foi feita a partir dos áudios gravados e de transcrições das falas dos sujeitos, bem como do prontuário de Ana. Também foram utilizados relatórios de visita à escola feitos pelos pesquisadores e relatórios de entrevistas clínicas realizadas pelas pesquisadoras coordenadoras.

Dependendo da forma que se aprende, a escola pode nomear os alunos como portadores de dificuldades, muitas vezes sem questionar seu próprio papel na formação dos modos de aprender. Isso ocorre porque a escola está, com frequência, preocupada em homogeneizar o aprendizado sem muitas vezes entender o processo que cada um desenvolve até atingir o nível desejado. Para além de uma aprendizagem mecânica, é importante entender que cada aluno possui um estilo cognitivo (KUPFER, 2012) e, portanto, um ritmo de aprendizado diferente do outro, bem como uma forma de se relacionar com o conhecimento que será muito particular. 0 que, com uma certa frequência, não se procura saber são os fatores envolvidos na causa da chamada "dificuldade". Causa esta que pode ser pensada como múltipla, gerada por diversos aspectos, por exemplo, o tempo que cada um tem para aprender, o significado que a família dá ao aprender e à escola, os significados atribuídos ao aprender pela instituição escolar e pela comunidade que o aluno frequenta.

0 problema neste texto se configura a partir de um questionamento: será que a aprendizagem esperada pela escola, muitas vezes em um modelo homogeneizador e rígido, poderia estar produzindo a chamada dificuldade de aprendizagem de Ana? Qual o papel da família e da própria Ana nessa nomeação? Para iniciar nossa resposta, discutimos dificuldades de aprendizagem, pois o termo é muito falado e talvez pouco debatido para quem fala e para quem o tem como diagnóstico. Além disso, também questionamos brevemente o movimento contemporâneo de medicalização da educação e se a nomeação de dificuldade de aprendizagem, no referido caso, poderia se relacionar a esse ethos, impactando seu desempenho e suas relações com o conhecimento e com os pares na escola.

Para começar, fazemos uma breve discussão sobre dificuldades de aprendizagem e fracasso escolar. Depois o artigo discorre sobre o aprender e o não aprender na grande diferença de os pensar como substratos de funções cerebrais ou como marcas da trajetória de cada um com o Outro, num enfoque onde o relacional é seu substrato.

Por fim, apresentamos o caso Ana trazendo a discussão e análise embasada nos quatro eixos formadores da pesquisa (sujeito-família-especialista-escola). A partir do caso, apontamos as 
noções de estilos cognitivos (KUPFER, 2012) e mal-estar (FREUD, 2011) como saídas menos biologizantes ao termo de dificuldades de aprendizagem.

\section{Contextualizando as dificuldades}

0 debate sobre fracasso escolar é antigo no Brasil, e envolve sobretudo uma busca sobre as causas da não aprendizagem e da não permanência de alunos na escola. Enquanto conceito, é mutável e situado em um determinado período histórico. Entende-se como fracasso escolar não somente o não aprender do aluno, mas também a legitimação, o reconhecimento oficial do lugar daquele que não aprende, ou melhor, refere-se também ao que diz a escola sobre esse aluno ou o que faz a respeito (NUNES; SILVEIRA, 2009).

Com a ampliação da escola, e o desenvolvimento das sociedades a partir dos séculos XIX e XX, surgiram também as dificuldades de aprendizagem. No Brasil, um país em crescimento onde a democratização passou a ser uma meta, a expansão do ensino teve também que se haver com o lema "para todos". Com a ampliação e a obrigatoriedade do ensino, a escola se deparou com um quantitativo grande de alunos e encontrou o desafio de lidar com a diversidade. Nesta ótica, aquele aluno que antes era excluído fora da escola por não ter oportunidade de acesso, passa a ser excluído dentro dela, pois não consegue responder satisfatoriamente ao esperado. É com este processo de ampliação que vão se verificar os processos de "produção do fracasso escolar" e da "pedagogia da repetência" (OLIVEIRA, 2007).

No célebre livro A produção do fracasso escolar: histórias de submissõa e rebeldia, Patto (1996) chama a atenção para a importância do debate histórico que considere o que a própria escola produz, fazendo uma crítica contundente à atribuição das causas do fracasso apenas a aspectos extraescolares. Individualizar o problema seria uma forma de atribuir à criança aquilo que a própria escola acaba por produzir. No entanto, ainda que essa crítica tenha tido um impacto importante no final do século passado, o século XXI assiste a um amplo ressurgimento da patologização do "fracasso" como sintoma individual. Proliferam-se os rótulos dados ao "aluno-problema" e uma série de classificações patológicas começam a surgir para explicar os entraves na aprendizagem e os problemas de comportamento. A medicalização surge e se insere rápida e intensamente no contexto escolar brasileiro, passando a caracterizar o sujeito como se ele fosse uma simples soma de características biológicas e comportamentais (CHRISTOFARI; FREITAS; BAPTISTA, 2015).

Na tentativa de intervir sobre os alunos que teriam dificuldades de aprendizagem, também surgiram a patologização e a rotulação daqueles que não avançavam, sobretudo ancoradas em modelos de desenvolvimento mais universais. Após anos de repetência, muitos dos alunos evadiam ou acabavam sendo mandados para classes ou escolas especiais, pois se acreditava que suas dificuldades eram algum tipo de deficiência (SANTIAGO; SILVA, 2014).

É também sob essa ótica que surgem metodologias específicas, às vezes consideradas ideais no sentido de atender a todos. A lógica universalizante exclui o contexto e o próprio sujeito da produção de determinadas ações. Numa espécie de ilusão psicopedagógica (LAJONQUIÈRE, 1999), acredita-se na possibilidade e necessidade de ajustar e adequar a intervenção adulta às capacidades e habilidades da criança, de tal forma que um bom método per se redundaria em boas aprendizagens. Acreditando na eficiência cabal do método, o sujeito fica esmaecido e os que não aprendem apresentam déficits individuais.

Nesse contexto, o termo dificuldade de aprendizagem passa a ser disseminado no cenário escolar. Nos anos 1960, as definições de dificuldades de aprendizagem se deram a partir de dois autores, Samuel Kirk e Barbara Bateman, que mais tarde serviram de apoio para as definições posteriores (CORREIA, 2007). 
Kirk (1962 apud CORREIA, 2007, p. 157) as definiu como:

[...] um atraso, desordem ou imaturidade num ou mais processos da linguagem falada, da leitura, da ortografia, da caligrafia ou da aritmética, resultantes de uma possível disfunção cerebral e/ou distúrbios de comportamento e não dependentes de uma deficiência mental, de uma privação sensorial, de uma privação cultural ou de um conjunto de factores pedagógicos.

Ainda que Fonseca (1995) aponte a falta de uma teoria sólida e consistente para a definição de dificuldade de aprendizagem e de uma taxionomia mais detalhada e compreensível, vemos que a ideia de disfunção cerebral e/ou desordem neurobiológica residem como pano de fundo. Por exemplo, podemos notar, a partir da citação de Kirk (1962 apud CORREIA, 2007), que a ideia de imaturidade sugere um processo individual, muitas vezes apoiado sobre uma disfunção cerebral. Neste sentido, ainda que haja uma clara distinção entre dificuldade de aprendizagem e deficiência mental, o substrato orgânico parece ter destaque. Faz-se importante ressaltar que quando uma criança e/ou um adolescente são diagnosticados, ou indicados, como apresentando dificuldades no aprender, sempre entrará em questão o mal-estar. Este pode estar predominantemente situado ao lado da escola, que muitas vezes se sente impotente para lidar com a situação, ou mais ligado à família, que pode se sentir fracassando na educação do filho, e, também, na própria criança e adolescente. Nesse sentido, a produção desse incômodo, que se faz entre $o$ sujeito e o mundo circundante, deve levar em conta essas múltiplas articulações. A questão é que, no contemporâneo, a supremacia da compreensão orgânica das causas daquilo que não vai bem na escola muitas vezes compreende o problema como sendo apenas do aluno.

Contemporaneamente, algumas formas de compreender as dificuldades selam definitivamente sua articulação ao orgânico. A ideia de distúrbio se associa à de transtorno, nome que aparece ao longo dos manuais diagnósticos, considerado um déficit de substância neuronal e entrando em cena, de modo compensatório, a medicação (DUNKER, 2014, p. 93). Para o National Joint Committee on Learning Disabilities (1988 apud FONSECA, 1995), por exemplo, as dificuldades de aprendizagem se associam a um distúrbio que está ligado ao sistema nervoso, podendo ocorrer durante a vida toda. Compreender a dificuldade, sobretudo por um viés organicista, não é sem consequências, já que se considera prioritária a estrutura biológica que sustenta um sistema, mais do que o sujeito e suas relações. Nesta ótica, quanto mais o orgânico ganha destaque, menos o subjetivo é levado em conta (GUARIDO; VOLTOLINI, 2009).

Fernandez (1991) fala da dificuldade de aprendizagem atravessando um corpo pulsional, portanto de um corpo que se constitui e está em permanente relação com o Outro. Não há em sua teoria a negação do orgânico, pelo contrário, já que ele se presentifica por suas fraturas, no entanto não há um orgânico que não seja regido por um corpo, já que "pelo corpo nos apropriamos do organismo" (FERNANDEZ, 1991, p. 58). Do início ao fim, a aprendizagem passa pelo corpo, "o corpo coordena e a coordenação resulta em prazer, prazer de domínio" (FERNANDEZ, 1991, p. 59). Dominar seria, então, uma forma se se apropriar. 0 organismo, com seus ritmos e metabolismos já codificados para além de nós próprios, com sistemas independentes, passa a ser um corpo representado e a representar.

No “Discurso de Roma”, Lacan (1998, p. 165) diz que "a linguagem não é imaterial. Ela é corpo sutil, mas corpo". Sendo corpo, nos indica que ela é forma, é através dela que podemos pensar no psíquico como um espaço. 0 que Freud (1980) já havia sinalizado ao pensar o psíquico como um dispositivo, ou seja, um aparelho que se forma como um escudo de defesa, um escudo protetor diante de uma avalanche energética excessiva, com pressão constante. O espaço constituído coloca "barreiras de contato" à inquietude excessiva da força (FREUD, 1980, p. 399). 
O aparelho psíquico, então, se constituiria como uma forma de fixar esse excesso e, assim, represá-lo de alguma forma, regulando-o. Contudo, como se daria essa fixação? Justamente através da representação. A pulsão sendo uma energia, desprovida de qualidade, não possui dimensão alguma, ela apenas é, força constante. Contudo, pela meta que visa e pelos objetos a que se liga, a pulsão conhece um "destino" essencialmente psíquico (LAPLANCHE; PONTALIS, 1992, p. 144). Ela poderá ser representada. Como a pulsão não tem um objeto prévio, será necessário a criação do objeto, portanto uma positivação dessa negatividade para que o objetivo possa se cumprir (WINE, 1999). Entretanto, como esse objeto poderá ser determinado? 0 objeto poderá ser positivado através do campo do inconsciente que se articula como uma linguagem. 0 que significa dizer que é apenas no campo ordenado da linguagem que ele poderá adquirir contornos, possuir algum sentido. Tudo isso é importante para dizermos que não existe uma inscrição do objeto orgânica, a "positivação do objeto já é uma consequência da travessia efetuada pelo impulso. Este último teria trazido ao inconsciente a energia necessária para executar o trabalho de determinar o objeto." (WINE, 1999, p. 20) O espaço da representação enquanto uma fixação da força, do impulso, a nomeia, ou seja, dá forma à dispersão pulsional. Assim, a linguagem seria uma forma de ordenar a dispersão, ela transforma a dispersão pulsional em ordem.

Toda essa discussão nos traz dois pontos fundamentais. 0 primeiro é que a aprendizagem da satisfação, desde os seus primórdios, não é regida pelo registro da necessidade, o que significa dizer que não está inscrita no orgânico. É no campo da linguagem, na relação com o Outro, que essa trajetória irá se dar. Segundo ponto: a inscrição da força pulsional nunca é definitiva, no sentido de existir uma perfeita adequação entre o objeto e as exigências pulsionais. Há sempre um resto que não pode se inscrever no campo representacional. Justamente o mal-estar irá denunciar essa im- possibilidade da perfeita medida, de adequação suficiente e definitiva.

Se o mal-estar é uma condição própria do humano, trata-se de refletir de que modos estamos lidando com ele na escola. A crescente dificuldade de lidar com a criança por parte das famílias, das instituições escolares e do serviço social parece proporcionar grande abertura para a prevalência do discurso médico no diagnóstico do mal-estar que a criança pode causar e enunciar na escola. A promessa de um medicamento certo para cada situação se oferece como tentativa de apagamento da condição pulsional da criança (KAMERS, 2013, p. 162).

\section{0 aprender, estilo de cada um}

Para a psicanálise, como já sublinhamos, o sujeito é constituído no interior do campo do Outro. Nenhuma produção subjetiva pode ser pensada fora desse campo. Pode-se assim dizer que as aprendizagens e a (re)construção do conhecimento socialmente compartilhado têm lugar no seu interior, pois são produções subjetivas de um sujeito que está constituído no interior do campo da linguagem (LAJONQUIÈRE, 2007). Ou seja, para que haja aprendizagem e a produção de conhecimento é preciso a interação com um outro, pois é nessa troca que o conhecimento vai sendo (re)construído e a aprendizagem vai sendo efetivada. São as experiências que cada um traz que fazem com que esses dois processos possam ocorrer.

Kupfer (2012), a partir de Lacan, sugere que em vez de problema pensemos em estilos cognitivos e assim ampliemos nosso olhar diante do processo que é o aprender. Estilos cognitivos possuem diversas definições e abordagens. Kupfer (2012, p. 63) vai dizer que esse termo "[...] passa a ser a peculiar relação de um sujeito com o particular objeto, o conhecimento". Essa relação vai trazer as marcas do estilo do aluno como sujeito dentro da relação com um outro, o professor. $\mathrm{O}$ estilo vai se construir em sucessivos encontros com os objetos de conhecimento. Nesse processo de construção dos objetos 
de conhecimento, a criança vai contemplar o Outro neste exercício, assim ela irá construir e se construir em seu estilo (KUPFER, 2012). Ou seja, o aluno quando contempla o professor dentro desse processo vai construir e se construir no seu estilo próprio de aprender. É na relação que ele faz com o professor que esse estilo vai sendo gerado e ganhando cada vez mais autenticidade por ser dele e de mais ninguém.

O que o professor transmite é o como, e é nessa relação com o objeto que vai ser transmitido seu próprio estilo, para ser "esvaziado" pelo aluno e ser novamente "preenchido" com o estilo do aluno que estará em construção (KUPFER, 2012). 0 estilo de cada aluno passará pela relação que ele tem com o professor e com o estilo deste professor. Ou melhor, a construção de seu estilo próprio passa pela relação com o Outro, a partir de um modelo identificatório com aquele que ensina. Nas brechas da identificação, ou seja, justamente no espaço da falta entre o eu e o outro, é que o sujeito poderá criar sua específica forma de aprender. $\mathrm{O}$ estilo, então, é um saber-fazer a partir da falta do Outro, sendo paradoxalmente uma forma de a obliterar (ORNELLAS, 2018). Se aprendemos a partir do Outro, a partir do afeto e da identificação com o professor, no discurso que nos oferece a cultura, é justamente para subverter esse já dado. Temos, então, que pensar em estilos de aprender, diferentemente de problema, fala mais de formas singulares de relações com o saber. Se estas formas trazem problemas, podemos perguntar para quem, em qual contexto.

Como já sublinhado, participar da cultura é necessariamente ter que lidar com um certo desconforto que as renúncias necessárias à vida em comum nos exigem. 0 mal-estar (FREUD, 2011) está referido à relação com o outro, seja a relação com pares ou com seu ideal. Esse mal-estar, inerente às relações sociais, pode ser enunciado de diversas formas no que diz respeito à escolarização. Ao não corresponder a certo ideal de aprendizagem, por exemplo, um aluno pode sentir-se mal pois sente que não consegue responder a determinada demanda, assim: "[...] o sentem como um doloroso mal-estar, uma espécie de angústia, quando se veem impedidos de executar determinadas ações" (FREUD, 2011, p. 82). Este trecho de Freud articula mal-estar a uma "espécie de angústia", no entanto este termo freudiano - que não é um conceito metapsicológico - aparece associado ao longo de sua obra a outros conceitos. 0 importante aqui é compreendermos que participar da escola enquanto instituição que exige a vida em comum sempre envolverá pontos de mal-estar. Outro aspecto importante é sabermos que o mal-estar não se liga necessariamente a algo negativo, pois se constitui nas relações que temos com os outros, com os pares, e às vezes pode ser impulsor para o sujeito se subjetivar, encontrar formas de fazer com ele.

Sob esta ótica, podemos enfatizar a importância de pensarmos a causalidade do aprender de forma sobredeterminada. Quando se pensa o que não vai bem no aprender tendo causa "numa possível disfunção cerebral e/ou distúrbios de comportamento" (KIRK, 1962 apud CORREIA, 2007, p. 157), localiza-se no neurobiológico a causa e entende-se "o déficit" como um distúrbio, no modelo da doença. A doença como uma matriz de compreensão da realidade vai para além do espaço médico, e ganha terreno nos diversos especialismos como psicólogos, fonoaudiólogos, psicopedagogos, "daí a substituição do termo medicalização por um outro mais abrangente - patologização -, uma vez que o fenômeno tem-se ampliado, fugindo dos limites da prática médica" (COLLARES; MOYSÉS, 2015, p. 26). Compreender o aprender na lógica binária da saúde/doença, tendo o biológico como substrato, diminui não só a participação da escola na sua produção, como do próprio sujeito. A fala, neste modelo, não é tida como um instrumento central no diagnóstico, muito menos de cura.

É sob esse pano de fundo que trazemos a história de Ana, diagnosticada com dificuldade 
de aprendizagem (entre outros transtornos). Fato é que, quando íamos à escola, quando fazíamos entrevista clínica com ela, víamos e nos relacionávamos com uma adolescente cheia de vida, com tiradas espirituosas absolutamente conectadas às situações vividas, leitora voraz de livros de vampiros. As interpretações perspicazes sobre a família e sobre a escola nos indicavam uma profundeza interpretativa surpreendente. Quando lemos o prontuário e ouvimos a família reafirmar dificuldade de aprendizagem, ficamos nos perguntando o que não estaríamos vendo, ou estaríamos vendo outra coisa? Esse ponto instigante nos fez seguir adiante.

\section{Ana}

O caso, como já referido, foi escolhido a partir do projeto de pesquisa Infância, adolescência e mal-estar na escolarização: estudo de casos em psicanálise e educação (CARNEIRO; COUTINHO, 2016), que se constituiu a partir de uma parceria entre o Núcleo Interdisciplinar de Estudo e Pesquisa para a Infância e Adolescência Contemporâneas da Universidade Federal do Rio de Janeiro (NIPIAC/UFRJ), as Faculdades de Educação da Universidade Federal do Rio de Janeiro (UFRJ) e da Universidade Federal Fluminense (UFF), com o Instituto de Psiquiatria (IPUB) da UFRJ, onde o trabalho se realizou, no Serviço de Psiquiatria da Infância e Adolescência (SPIA). Teve como objetivo principal investigar o mal-estar na escolarização de crianças e adolescentes a partir da metodologia de pesquisa-intervenção e estudo de casos.

A pesquisa-intervenção nas ciências humanas parte da premissa comum de que os sujeitos humanos se constituem no âmbito das práticas de significação, sempre numa situação partilhada com outros, sejam adultos, jovens ou crianças (CASTRO; BESSET, 2008). Dessa forma, a palavra ou qualquer ação do pesquisador se realiza na interlocução continuada com os sujeitos através da construção de sentidos para as situações vividas. Assim, o sujeito que investigamos é efetivamente constituído ao longo do processo de pesquisa por meio da interlocução com o pesquisador ou com outros que também se incluem na forma como essa experiência se produz.

Em tais pesquisas, consideramos que os sujeitos pesquisados (crianças, adolescentes, pais, professores, especialistas) não podem estar excluídos do processo de construção de um saber sobre eles mesmos. Sendo assim, passamos de uma posição de pesquisar os sujeitos para a posição de fazer pesquisa com eles, colocando em questão a própria relação (assimétrica) entre o pesquisador e os seus objetos de investigação.

O material do caso de Ana foi produzido durante os anos de 2013 e 2014, a partir de reuniões com os pais da adolescente, a própria adolescente, idas à escola onde ela estudava e dos médicos/especialistas que a atenderam no IPUB-UFRJ. 0 registro e a construção do material foram feitos por meio dos áudios gravados e de suas transcrições, dos relatórios, bem como do prontuário de Ana. Ou seja, é sobre o discurso direto dos participantes, bem como dos relatórios e das observações participantes, que se debruçou a análise.

A adolescente iniciou o acompanhamento no SPIA em agosto de 2012 com a queixa de Transtorno do Déficit de Atenção com Hiperatividade (TDAH), Transtorno Opositivo Desafiador (TOD) e dificuldade de aprendizagem. Foi a família quem trouxe a questão da dificuldade de aprendizagem para o grupo nos encontros que foram feitos mensalmente e foi a partir do discurso da família e pelo discurso de Ana, juntamente com idas à escola da adolescente, que surgiu o interesse em saber mais sobre a dificuldade de aprendizagem nesse caso, ampliando uma visão que a tomava como fato. Para tanto, foi feita uma análise dos quatro eixos formadores da pesquisa que são, como já dito, a família, o sujeito, a escola, e os especialistas. Se os eixos fizeram parte do design da pesquisa e orientam a escrita deste artigo, é porque se configuraram como uma estratégia metodológica analítica e 
de organização, no entanto, as intervenções se deram para além desses eixos. Isso significa dizer que foram simultâneas no tempo, muitas vezes aconteceram em conjunto e não exatamente na forma discriminada a seguir.

\section{Histórico do caso de Ana}

Ana é adotada desde o primeiro ano de vida e ficou com a mãe biológica somente até os oito meses. Possui uma história de abandono e maus-tratos enquanto estava com a mãe biológica, foi preciso a ida do Conselho Tutelar por mais de três vezes e somente na quarta vez tiraram a menina da casa da mãe. O bebê estava em péssimas condições de higiene, sem vacinas, abaixo do peso e com lesões dermatológicas. Vizinhos teriam denunciado essa situação. Depois da adoção ela não teve contato com a mãe biológica, cujo rumo é desconhecido e tem histórico de dependência química e abandono de outra filha. 0 pai biológico não tem história conhecida. Aos oito meses só sentava; com um ano andou sem apoio; suas primeiras palavras foram com mais ou menos um ano e meio. Sua mãe a comunicou sobre a adoção quando Ana tinha quatro anos, pois a menina, vendo uma professora grávida, a questionou se tinha nascido da sua barriga. Sua mãe disse que a mãe biológica tinha adoecido e morrido e que Ana era sua filha do coração.

Durante o segundo ano de pesquisa, Ana tinha 15 anos e estava no nono ano do Ensino Fundamental em uma escola particular. A configuração de sua família é composta por pai e mãe adotivos e tem uma irmã biológica que mora em outro estado brasileiro. Ana já foi atendida por outros psicólogos antes de chegar ao SPIA. Em seu primeiro psicólogo, os pais só levaram Ana umas quatro a cinco vezes e depois desistiram. Aos seis anos ela foi levada à psicoterapia, por causa de seu comportamento agitado na escola, e ficou por lá mais ou menos um ano. Aos sete/oito anos fez arteterapia com uma psicóloga por mais ou menos seis meses. Foi por encaminhamento do Instituto de Puericultura e Pediatria Martagão Gesteira (IPPMG) que deu entrada no SPIA em 2012 e sua chegada se deu por uma suspeita de TDAH, TOD e dificuldade de aprendizagem.

\section{Eixo sujeito}

O eixo sujeito contempla as falas de Ana em relação à escola, ao que a incomoda, o que gera de alguma forma mal-estar. As falas foram retiradas de reuniões realizadas com a adolescente para que pudesse falar sobre questões que a incomodavam com relação a sua escolarização. No entanto, pudemos verificar que entre as queixas da escola também havia algumas reclamações em relação a sua mãe. 0 objetivo deste eixo foi justamente proporcionar um lugar de fala para a adolescente, pois somente o discurso dos pais e da escola eram os que vigoravam.

Ana fala de a escola ser chata, pois na outra escola é que estavam seus amigos e a estrutura era bem melhor, tinha cadeira estofada, ar condicionado e projetor: "Chata. Os meus outros amigos ficaram tudo na minha outra escola e é o maior calor. Os outros ficaram na outra, que era adventista. Cadeira estofada, ar condicionado, projetor."

Diz que o grupo de pesquisa poderia ajudá -la em relação a um menino que a incomodava e toda vez ela precisava descer na coordenação para dar queixa: "Tem um menino na minha sala que é muito chato. Toda vez eu tenho que descer na coordenação por causa dele."

E completa: "Ele fica me irritando, me apelida e uma vez ele tentou bater em mim."

Em nenhum momento Ana diz precisar de ajuda para estudar ou fala de ter alguma dificuldade para aprender.

Em relação a repetir o ano escolar, Ana diz ser por brigas: "Mas eu já repeti o terceiro ano. Já era pra estar no nono. Repeti pela mesma coisa nesse ano, pessoal começa a implicar comigo e eu não sabia o que fazer e brigava."

Com essa fala fica mais claro que o problema para a menina não é compreendido como 
cognitivo, pois ela enunciou que o fato de ter repetido o ano escolar foi por não saber lidar com a implicância de seus colegas de turma, assim partia para a briga.

Ana tinha uma boa relação com o pai, mas nem tanto com a mãe. Em uma das reuniões feitas com ela, quando a pesquisadora perguntou sobre o pai e por que ele se importava tanto com os estudos, ela respondeu: "Meu pai é um pai coruja."

Já com a mãe as coisas eram mais complicadas, e a menina disse que:

Ela não gosta muito de vir aqui [se referindo ao SPIA/IPUB/UFRJ], não gosta de buscar o boletim, não gosta de ir na minha escola. [...] É tanta reclamação, que ela prefere nem mais ir. [...] Na época... quando eu tava nessa escola eu descia muito [pra direção, coordenação], já fui três vezes pra T., duuuuuas... acho que umas sete vezes pra T., três pra $\mathrm{V}$. e pra diretoria.

Esse era o motivo para reclamarem muito dela, o fato de sempre estar na sala da direção ou da coordenação. A mãe, exausta pelas reclamações, deixou de participar da vida escolar da filha.

A menina relatou que o professor de Geografia uma vez a mandou ficar de cara para parede do "nada" e ela não ficou, por isso a mandou descer e, assim, começou a ganhar fama de bagunceira. Ela fez uma música zombando do professor que repercutiu tanto que ela diz que o professor se demitiu por causa dela.

O professor de Geografia me pegou e me colocou virada de cara pra parede e disse que eu não podia mais sair de lá. Aí eu fui e disse: 'Professor, eu não fiz nada'. Aí eu fui sentar na minha cadeira, aí ele foi e me mandou descer. [...] Aí na aula dele eu comecei a zoar ele e foi aí que eu ganhei essa fama de garota bagunceira. Eu fiz ele se demitir. [...] Eu fiz uma música, aí ele ficou com raiva e passou pra turma da manhã. Xingou uma menina de lésbica e foi demitido.

Nessas falas, Ana se sente poderosa por achar que ela fez o professor se demitir. Quando alguém faz algo que não a agrada ela devolve não respeitando e faz bagunça para atingir o outro. A "fama" de Ana como bagunceira parece marcar um lugar para ela diante do grupo que não só acha graça, mas a percebe corajosa.

0 assunto das notas é sempre muito falado pelos pais e Ana diz como a mãe reagiu quando foi contar para o pai sobre a nota da prova: "Tava olhando pra cara do meu pai, né, danada. Ela ficou olhando pra cara do meu pai. Eu falei pra ele que tirei nota boa, ela ficou assim: 'Duvido, duvido'.'

A mãe fala que as notas boas ela mostra, mas que as ruins ela nem fala, e Ana rebate dizendo que contou, sim, para o pai a nota baixa que tirou em Ciências.

Mas eu falei pro meu pai que tirei nota baixa, também falei pra ele que tirei nota baixa em Ciências. A professora falou que tô me dando bem na matéria, só que eu não consegui pegar direito. Porque quando ela tava fazendo a averiguação no quadro eu tava respondendo direito, mas quando eu fui fazer a prova eu senti dificuldade. Mas ela falou que vai fazer trabalho bimestral do livro.

Ana fala de uma dificuldade com Ciências, mas não fica claro em sua fala se isso seria algo recorrente ou se foi apenas um episódio de determinado conteúdo ou ansiedade por estar sendo avaliada, pois quando respondeu para a professora na aula estava indo bem.

A leitura é presente na vida de Ana. A mãe diz que ela lê um livro em dois dias. A pesquisadora pergunta à menina sobre o assunto do último livro que tinha lido: "Era um livro sobre mitologia. Eu gosto de ler, é bom."

Ana diz estar gostando de ler coisas sobre psicose e maníacos: "Você tem que ter uma mente aberta pra ler o livro. Imagina você ler um livro sobre drama, se você não entende o papel da pessoa, da vítima, você não consegue entender o livro. [...] Eu tô fazendo um livro."

Para uma menina que tinha um diagnóstico de "transtornos" e dificuldade em aprender, o aprofundamento interpretativo dessa frase chama a atenção. Não só ela se diz capaz de se colocar no lugar do outro, a vítima, como está escrevendo sua própria história. Os livros de vampiros, terror e sangue que ela gostava não eram reconhecidos nem pela escola nem pela 
família. Se o livro sugerido pela escola era Diários de uma Princesa, como legitimar isso com o qual ela justamente se opunha?

Em uma das reuniões que tivemos com Ana ela fala da possibilidade de trocar de escola e diz que tem uma que é muito ruim e quebrada e a outra onde só tem arrumadinho. Quando perguntamos o que ela acha da escola, Ana diz:

Um saco. Escola não é pra ser legal, nenhuma escola é legal.

\section{[...]}

Tem matéria que eu gosto e professor que é 'macumbado', a maioria é de encher o saco do que legais. Tem matéria preferida, tem! Tem gente que eu não gosto, tem! Tem inspetores que enchem o saco, tem! Tem diretora que é legal com você, tem! Tem a que enche o seu saco, tem! Tem, tem tudo.

Pelas falas de Ana podemos perceber que há uma reclamação em relação à escola. A menina sempre reclamou da escola nas reuniões, de estar sempre a mesma coisa ou o mesmo "porre". Todavia, ao mesmo tempo, tem matéria preferida e diretora legal, indicando que a escola, assim como a vida, vai ser marcada por tensões e ambivalências.

\section{Eixo família}

Este eixo abarca as falas dos pais de Ana, de como eles viam a filha em seu processo de escolarização. As falas foram retiradas de reuniões feitas com os pais de Ana para que eles pudessem falar o que os incomodava em relação à filha e à escola. 0 objetivo deste eixo foi de proporcionar um espaço de fala e de troca entre os pais, para que situações que os incomodavam pudessem ser resolvidas e faladas. Algumas vezes foram feitas entrevistas individuais, justamente para se trabalhar com aquilo que gerava mal-estar e discordância entre o casal. Outras vezes, eles participaram do grupo de pais, junto com os demais pais do projeto.

0 pai de Ana, Francisco, ${ }^{2}$ na primeira reunião

2 Nome fictício. que o grupo realizou com os pais, falou de como a filha estava no colégio e disse que ela tinha falta de atenção, não conseguia se concentrar:

Vocês vão ter oportunidade de conversar com a Ana. Vocês vão ver que ela é normal, se tiver que ser uma pessoa louca, sou eu. Porque todo mundo fala: 'a Ana é normal'. A Ana só é aquela criança que faz o que quer. Mas eu falo para ela, isso não é normal, o mundo não é assim. Aí eu falo para ela que quando a gente faz só o que quer, tem que estar preparado para receber, porque toda ação tem uma reação. Você não pensa que vai estar preparada para o mundo já. A gente tenta colocar isso na cabeça dela, mas... não dá!

Nessa fala, o pai diz que a filha é normal, depois ele traz a fala de pessoas de fora que também dizem que a menina é normal. É como se estivesse tentando aceitar isso e não o contrário, como se trazendo a fala de pessoas de fora reforçasse o que disse anteriormente, que a filha é normal, e para ele isso é importante e faz com que aceite essa ideia e não outra. Contudo, esta fala também aponta para uma certa dúvida: ela é normal?

As reclamações escolares sobre o comportamento de Ana são frequentes e o pai fala: "Sempre aquele negócio. Ela é inteligente, mas não tem atenção."

Há um reconhecimento do pai em relação à filha quando o assunto é a escola, mas há algo no comportamento da menina que faz com que ela não consiga obter o que é esperado dela. Para Francisco, a menina não precisa de remédio. Quando força a barra com ela, ela faz o que tem que fazer. E diz que: "Eu só quero que a Ana goste de estudar, porque o que leva as pessoas pra frente é o estudo, nada mais. [...] Não esquento de bagunça, só com as notas dela."

As notas são sempre um assunto recorrente nos discursos do pai e da mãe. Em todas as reuniões o pai falou sobre isso, e a mãe, Roberta, ${ }^{3}$ também falou dessa questão. Disse que Ana mostra as provas boas e as que tira nota baixa nem toca no assunto: "Quando ela tirava nota boa em redação, por que eu sei que ela é boa nisso, ela trazia, ficava mostrando, mas

3 Nome fictício. 
não falava pra gente que tava tirando zero em Matemática."

Para o pai, a questão que mais o incomoda são as notas. Ele teve que trabalhar quando criança, o que segundo ele o atrapalhou nos estudos. Como economicamente sua filha não precisa trabalhar, ele não compreende porque não tira dez. Francisco insiste na ideia de que a filha precisa tirar dez em tudo na escola, pois como ela só estuda, ele diz que é possível tirar a nota máxima. E fala para a filha: "Ana, o que eu quero de você, eu só peço a você que você estude. Essas notas ruins aí, até falei: 'Oh, oito, nove e dez. Eu prefiro dez'” Então a mãe fala: “Não, mas nove tá bom." Ele diz: "Não, nove tá bom de quem trabalha, pra quem trabalha, nove, oito, sete, mas quem não trabalha é dez."

As notas são sempre um assunto recorrente nos discursos do pai e da mãe. Para esta família, o sucesso na escola seria garantido pelo dez? Todas as vezes que a filha não obtivesse esta nota estaria fracassando no olhar dos pais? 0 mal-estar gerado pela não correspondência da filha ao que esperavam poderia estar remetido também ao que falhavam? Ou seja, também eles não seriam pais nota dez?

Ao longo dos dois anos de intervenção, a fixidez do dez pareceu ter esmorecido um pouco, ainda que as notas sempre apontassem para um certo mal-estar. Numa reunião do ano seguinte o pai disse: "Eu desisti do dez."

A mãe confirma e diz que desistiram do dez há muito tempo. Roberta fala que a nota que Ana tira não é para ser dos pais. 0 pai precisa entender que aquilo não é uma moeda de troca. A mãe fala de a menina seguir seu próprio caminho e entende o que precisa fazer quando diz: "Quando ela repetir, repetiu e pronto!"

Francisco, ao final do segundo ano de nossos encontros, parece flexibilizar o dez dizendo:

Já vi que não vai sair dez mesmo, o dia que sair tá bom. Se sair tá bom, se não sair também tá bom. Eu amo minha filha assim que tire dez, que tire zero. Eu amo, eu só quero o melhor pra ela. Só isso que eu quero. Quando a gente quer que um filho estude, não quer que o filho estude pra gente.
Em termos da intervenção, essa fala do pai é importante, pois demonstra certo deslocamento discursivo. Com os encontros e as conversas talvez ele tenha podido perceber que a filha nem sempre iria corresponder às expectativas dele nem da mãe a todo o momento. Para além do aspecto interventivo, hipotetizamos que a angústia dos pais diante das notas e da distância entre a filha real e a imaginada tenha interferido muito na trajetória de especialismos que Ana teve. Na dúvida entre a filha "ser normal" ou não para aprender, a busca por um especialista que, enfim, a fizesse tirar boas notas mobilizou uma longa caminhada. Nessa caminhada, alguns profissionais a compreenderam como "transtornada", outros não, como leremos a seguir.

\section{Eixo especialista}

Neste eixo os sujeitos participantes foram os psicólogos e psiquiatras que atenderam Ana no SPIA. As falas foram retiradas do prontuário de Ana e também de reuniões realizadas com os especialistas. 0 objetivo foi ampliar a discussão sobre o mal-estar. Aqui é importante ressaltar que quando ela chega na instituição, já havia passado por outras, e os diagnósticos já trazidos (tanto ditos pela escola, como por outros especialistas) foram narrados pelos pais.

0 primeiro especialista que atendeu Ana foi Arnaldo, ${ }^{4}$ psiquiatra do IPUB, que fala da menina como uma pessoa que não tem uma dificuldade de aprendizagem efetivamente, mas que o seu problema seria mais uma dificuldade de convivência. Por todas as escolas que passou, Ana é tida como muito inteligente, mas no ano de 2012 ficou em quase todas as dependências. Enquanto o pai vê discrepância no que dizem e o que realmente acontece, Arnaldo não vê nada de muito grave em relação ao aprender.

Arnaldo não concorda com o diagnóstico de TDAH, mas que ela é uma criança eminentemente motora:

4 Nome fictício. 
Eu acho que pela menina ter uma coisa de agitação, ela é muito motora, eu não sei se eu classificaria, pelo o que eu tô vendo aqui, como TDAH, mas ela é uma criança eminentemente motora. Talvez, uma coisa que a gente vê muito, quanto menos verbal, mais motora. Então, por ela não falar muito, ela transfere isso pra coisa motora. Ela prefere brincadeiras e jogos muito de corrida, ela prefere atividades físicas muito motoras.

A ação aqui descrita poderia estar mostrando justamente um esforço do corpo para representar? Ou seria uma forma mais direta de escoamento do afeto como descarga? 0 fato é que, ao brincar, ainda que de corrida, temos um Outro com o qual disputamos, um bom uso da aceleração do tempo que precisamos aprender, um domínio de movimentos. Ana, através da ação, parece também escrever sua particular história no aprender.

Depois de ser atendida por Arnaldo, Ana fica um tempo sem ir ao IPUB para atendimentos e em 2014 volta com a psicóloga Marta. ${ }^{5}$ Em seu primeiro dia, Marta relata a chegada da menina perguntando se ela sabia o motivo de estar lá: "A. disse que é por causa de comportamento, disciplina e mentalidade."

A menina fala de uma tentativa de mudança em seu jeito, que ficou mais estudiosa e mesmo assim ficou para recuperação, mas como não teve reconhecimento, desistiu: "A. diz que é impulsiva, repulsiva, mentirosa e que é assim por causa da sua história."

Ana fala de brigas na sala de aula, e que se a professora não gostasse, isso seria mais uma coisa pra sua ficha. Marta pergunta o que tem na ficha e ela diz que tem expulsões, brigas com a professora. Ana diz que isso tudo acontece por causa da sua raiva e porque todos na escola gostam de irritar. "Pergunto por que ela tem raiva e A. diz que é tipo um dom, já é dela, da personalidade [...] A. diz que tem faltado aula e tido 'mau comportamento', responde aos professores. Pergunto por que e A. diz que precisa descontar a raiva que ela imprime".

A menina fala que tem dois lados, um bom e

5 Nome fictício. outro mau, e dependendo do dia, um está mais presente que o outro. Marta fala para a menina dizer mais especificamente que raiva é essa e ela responde que não pode porque explode e fica rude. Ana diz que a ida à psicóloga era de início para controlá-la, mas depois achou que era para entendê-la e agora acha que é para ajudá-la.

\section{Eixo escola}

Neste eixo o material foi construído a partir do que havia no prontuário de Ana, que são alguns relatórios da escola e também das idas à escola, onde foram entrevistados alguns professores da menina e a orientadora pedagógica. 0 objetivo deste eixo é entender o motivo de tantas queixas e reclamações da menina e dialogar com a escola a partir do que encontramos em todos os outros eixos de análise.

Em 23 de agosto de 2012, a professora I. faz uma reclamação via formulário para a orientação pedagógica da escola L. C., onde Ana estuda: "Aluna indisciplinada, provocando tumulto e falta de vontade de acompanhar a aula, se rabiscando, batendo no colega, levantando o dedo para outro colega e uivando na sala."

Em mais um relatório, sem identificação nem data, nenhuma mudança em seu comportamento.

A aluna apresenta um comportamento agitado,
não realiza tarefas solicitadas, na maioria do
tempo mantém-se distraída com outras coisas,
como, por exemplo: pintar alguma coisa de for-
ma aleatória no caderno. A mesma apresenta
dificuldade no relacionamento com os colegas,
sendo complicado uni-la a outros colegas para
realização de trabalho em grupo. Quanto ao re-
lacionamento com o professor, a aluna algumas
vezes não aceita a solicitação do mesmo e desa-
cata, quando em aula, algumas vezes verbaliza
algo que não faz parte do contexto da mesma e
acha graça ao fazê-lo.

0 termo agitação é usado em todos os relatórios, mas em nenhum deles há a especificação do que eles entendem por agitação. Nos relatórios, que foram anexados junto com seu prontuário no IPUB, há sempre a mesma 
reclamação de que Ana não consegue acompanhar o que é dado em aula por causa de seu comportamento. Nestes não há o relato direto de que Ana possui algum tipo de dificuldade de aprendizagem, mas fica subentendido quando o termo agitação é articulado a "não consegue entender o que está sendo explicado e logo possui uma dificuldade para aprender determinados conteúdos".

Em uma das idas à escola de Ana conversamos com os professores de Inglês, Matemática e História. A professora de Inglês disse que Ana não para quieta e que não faz nada em sala. 0 professor de Matemática foi o que mais conversou e o que mais se mostrou interessado no caso dela. Ele disse que Ana não tem nenhum problema, não faz o dever porque não quer. E ainda diz que: "Parece que ela quer ficar nas trevas, não quer encontrar a luz."

Esse discurso do professor é bastante enigmático e, de certa forma, interessante. Para além de um juízo de valor, ele foi o único que pôde falar da participação dela em algo que remete ao mal-estar na escola: "parece que ela quer ficar nas trevas", dando a entender que de alguma forma "as trevas" fazem sentido para ela. Como boa leitora de histórias de vampiros, amando o preto e detestando o rosa, o professor de matemática parece ler alguma coisa que faz parte do estilo de Ana. Sendo um evento isolado e rapidamente substituído por "ela não para quieta, não copia etc.", nos parece, lamentavelmente, que os professores não puderam partir desse ponto, incluir o valor das trevas e dos vampiros como aspectos sensíveis em seu desejo por conhecer. Reiterando tanto a importância dos Diários de uma Princesa, quanto patologizando sua inquietude, os educadores pareciam falar e fazer mais do mesmo: constatar o quanto ela era "transtornada" e não conseguia aprender.

\section{À guisa de conclusão}

Iniciamos pretendendo compreender o caso de Ana em relação ao diagnóstico já dado de dificuldade de aprendizagem. Perguntamonos se a aprendizagem esperada pela escola, muitas vezes em um modelo homogeneizador, estaria produzindo a chamada dificuldade de aprendizagem e qual o papel da família e da própria Ana nessa nomeação. Indo num sentido contrário do entendimento de um diagnóstico fechado, optamos por nos orientar pelo termo mal-estar, na tentativa de aprofundar o que incomodava a adolescente e seu entorno.

Ao analisar os discursos dos diferentes eixos (sujeito-família-especialista-escola), pudemos ver que o mal-estar apareceu de diferentes formas, mas sempre relacional. Neste caso é perceptível, por meio das falas, que o mal-estar não estava somente em Ana, ou na escola, aparecendo em todos os sujeitos que faziam parte da vida da adolescente. Os pais, muito tomados por um discurso de filha e aluna nota dez, angustiados em exercer a parentalidade, fizeram da nota máxima o único índice seguro da aprendizagem suficiente. Os educadores, talvez cansados e atribulados, endossaram um discurso da menina "portadora de patologia" e em nenhum momento, ao longo dos dois anos, deram indícios de questionar também o lugar da escola na produção desse mal-estar. Ana, por sua vez, enunciava como era difícil lidar com a raiva e com a relação com os pais e os pares na escola. Todos tinham em comum uma certa queixa. A convergência dos discursos nos leva a dizer, então, que predominaram os ditos queixosos onde existiriam "culpados" fora do próprio sujeito, da escola e da família, sobretudo no primeiro ano de intervenção. Neste caso, pode-se pensar que o mais difícil talvez seja favorecer uma mudança neste tipo de discurso dessubjetivado, já que distante de uma reflexão de sua própria implicação no mal-estar. Hipotetizamos que nessa lógica em que o sujeito entra menos em cena, o ethos medicalizante é bem-vindo justamente porque oferece uma explicação e uma oferta de cura mais objetalizadas, supostamente rápidas e controláveis.

A compreensão do aprender e seus entraves, em que predomina uma leitura neurobiológica 
de disfunção, incrementa a exaltação de um sentido orgânico como fundamento daquilo que não vai bem. Tal leitura também concorre para um apagamento do corpo pulsional, aquele que não pode ser reduzido ao organismo e que traz as marcas constituintes do sujeito em sua relação com o Outro.

Pensando as questões do aprender como relacionais, trazemos os estilos cognitivos e estilos de aprendizagem como termos alternativos para a compreensão das chamadas dificuldades de aprendizagem. Para além de pensar as dificuldades como articuladas a algum déficit, a ideia de estilo envolve o sujeito em algo que lhe é próprio. Positiva um saber concordando que todos têm inteligência; a diferença repousaria no uso que podem fazer dela. Este ponto de vista iria num sentido contrário à patologização do aprender, que estaria de mãos dadas com os novos transtornos.

\section{Referências}

BRASIL. Conselho Nacional dos Direitos da Criança e do Adolescente (CONANDA). Resolução no 177, de 11 de dezembro de 2015. Dispõe sobre o direito da criança e do adolescente de não serem submetidos à excessiva medicalização. Brasília, DF, 2015. Disponível em: https://www.conass. org.br/ci-n-233-publicada-a-resolucao-conandan-177-que-dispoe-sobre-o-direito-da-criancae-do-adolescente-de-nao-serem-submetidos-aexcessiva-medicalizacao/. Acesso em: 23 jan. 2020.

CARNEIRO, C. 0 estudo de casos múltiplos: estratégia de pesquisa em psicanálise e educação. Psicologia, São Paulo, v. 29, n. 2, p. 314-321, 2018.

CARNEIRO, C.; COUTINHO, L. G. Infância, adolescência e mal-estar na escolarização: interlocuções entre a psicanálise e a educação. Psicologia Clínica, Rio de Janeiro, v. 28, n. 2, p. 109-129, 2016.

CASTRO, L.; BESSET, V. (org.). Pesquisa-intervenção na infância e juventude. Rio de Janeiro: Trarepa/FAPERJ, 2008.

CHRISTOFARI, A. C.; FREITAS, C. R.; BAPTISTA, C. R. Medicalização dos modos de ser e de aprender. Educação \& Realidade, v. 40, n. 4, p. 1079-1102, 2015.

COLLARES, C. A. L.; MOYSÉS, M. A. Preconceitos no cotidiano escolar: a medicalização do processo ensino-aprendizagem. In: CONSELHO REGIONA DE PSICOLOGIA DE SÃO PAULO (CRP-SP); GRUPO INTERINSTITUCIONAL QUEIXA ESCOLAR (GIQE) (org.). Medicalização de crianças e adolescentes: conflitos silenciados pela redução de questões sociais a doenças de indivíduos. São Paulo: Casa do Psicólogo, 2015. p. 221-244.

CORREIA, L. M. Para uma definição portuguesa de dificuldades de aprendizagem específicas. Revista Brasileira de Educação Especial, Marília, SP, v. 13, n. 2, p. 155-172, maio/ago. 2007.

DUNKER, C. A neurose como encruzilhada narrativa: psicopatologia psicanalítica e diagnóstica psiquiátrica. In: ZORZANELLI, Rafaela; BEZERRA JUNIOR, Benilton; COSTA, Jurandir Freire (org.). A produção de diagnósticos em psiquiatria contemporânea. Vol. 1. 1. ed. Rio de Janeiro: Garamond, 2014. p. 69-106.

FERNANDÉZ, A. A inteligência aprisionada. Abordagem psicopedagógica clínica da criança e sua família. Porto Alegre: Artmed, 1991.

FONSECA, V. Introdução às dificuldades de aprendizagem. 2. ed. rev. aum. Porto Alegre: Artes Médicas, 1995.

FREUD, S. Mal-estar na civilização. Trad. Paulo César de Souza. São Paulo: Companhia das Letras, 2011.

FREUD, S. Projeto para uma psicologia científica. In: FREUD, S. Edição Standard Brasileira das obras psicológicas completas de Sigmund Freud, vol. I. Rio de Janeiro: Imago, 1980. p. 385-529.

GUARIDO, R; VOLTOLINI, R. O que não tem remédio, remediado está? Educação em Revista, v. 25, n. 1, p. 239-263, 2009.

KAMERS, Michele. A fabricação da loucura na infância: psiquiatrização do discurso e medicalização da criança. Estilos da Clínica, São Paulo, v. 18, n. 1, p. 153-165, jan./abr. 2013.

KUPFER, M. C. M. Problemas de aprendizagem ou estilos cognitivos? Um ponto de vista da psicanálise. In: RUBINSTEIN, E. (org.). Psicopedagogia: uma prática, diferentes estilos. 4. ed. São Paulo: Casa do Psicólogo, 2012. p. 55-66.

LACAN, J. Função e campo da palavra e da linguagem na psicanálise. In: LACAN, J. Escritos. São Paulo: Perspectiva, 1998. p. 238-324.

LAJONQUIÈRE, L. De Piaget a Freud: para repensar as aprendizagens. A (psico) pedagogia entre o 
conhecimento e o saber. 14. ed. Petrópolis, RJ: Vozes, 2007.

LAJONQUIÈRE, L. Infância e ilusão (psico)pedagógica. Petrópolis, RJ: Vozes, 1999.

LAPLANCHE, J.; PONTALIS, J. B. Vocabulário de psicanálise. São Paulo: Martins Fontes, 1992.

NUNES, A. I. B. L.; SILVEIRA, R. N. Psicologia da aprendizagem: processos, teorias e contextos. Brasília, DF: Liber Livro, 2009.

OLIVEIRA, R. P. Da universalização do ensino fundamental ao desafio da qualidade: uma análise histórica. Educação \& Sociedade, Campinas, SP, v. 28, n. 100, p. 661-690, out. 2007.

ORNELLAS, M. de L. S. Estilo: marca que oblit era a falta do outro. In: Estilos da Clínica, São
Paulo, v. 20, p. 100-110, 2018.

PATTO, M. H. S. A produção do fracasso escolar: histórias de submissão e rebeldia. São Paulo: T. A. Queiroz, 1996.

SANTIAGO, A. L.; SILVA, M. M. M. Da universalização à qualidade de ensino: desafios da alfabetização. RevistAleph, ano XI, n. 22, p. 157-172, dez. 2014.

WINE, N. O sujeito entre o tempo e o espaço. 1999. 236 f. Tese (Doutorado em Teoria Psicanalítica) - Programa de Pós-graduação em Teoria Psicanalítica, Instituto de psicologia, Universidade Federal do Rio de Janeiro (UFRJ), Rio de Janeiro,1999.

Recebido em: 25/07/2020

Aprovado em: 09/12/2020

Este é um artigo publicado em acesso aberto sob uma licença Creative Commons. 